\title{
Identificação de cães potencialmente transmissores de brucelose na Zona Oeste da cidade do Rio de Janeiro
}

\section{Identification of dogs potentially transmitters of Brucellosis in west zone of Rio de Janeiro City}

\author{
Ismar Araujo de Moraes, ${ }^{\star}$ Henrique Farias Laranja, ${ }^{\star \star}$ Dala Kezen Vieira, ${ }^{\star \star \star}$ Silvio P. Lopes, ${ }^{\star \star \star \star}$ Alda Freaza, ${ }^{\star \star \star \star}$ \\ Glauco Melo, ${ }^{* \star \star *}$ Valfredo Penchel ${ }^{* \star \star *}$
}

\section{Resumo}

Considerando o fato de que a grande maioria dos cães infectados por Brucella canis e $B$. abortus são assintomáticos e diante do potencial zoonótico da Brucelose, entende-se que é grande o risco de transmissão seja entre cães ou destes para o homem. Com intenção de estudar a prevalência da B. canis na Zona Oeste da cidade do Rio de Janeiro, conduzimos um experimento onde foram utilizados 119 cães sem raças definidas, de ambos os sexos e idades variadas, originários dos bairros que compõem esta região da cidade. A partir de amostras de sangue total, obtidas por venopunção, extraiu-se o soro para a condução da técnica de soroaglutinação em placa para a identificação de soropositividade para $B$. abortus e para a técnica de imunodifusão em gel de agarose para a identificação de aglutininas para $B$. canis. Observou-se que $9,2 \%(n=11)$ dos animais foram reagentes para $B$. canis e que não houve reação de positividade para $B$. abortus em qualquer dos animais testados. Os resultados permitem concluir que é necessário despertar a consciência dos médicos-veterinários e criadores para o risco potencial representado pelos animais de companhia não testados para a presença da Brucella, e ressalta a necessidade premente do controle dessa zoonose.

Palavras-chave: brucelose canina, Brucella canis, Brucella abortus.

\begin{abstract}
Considering the fact that most of dogs infected with Brucella canis and B. abortus show no symptoms of the disease and in the face of Brucellosis's zoonotical potential, we imply that the infection risk is great among dogs and from dogs towards men as well. Intending to study the prevalence of $B$. canis in the western district of Rio de Janeiro city, we conducted an experiment with 119 dogs of non-specific breed, both male and female, ages varying, native of that region in Rio de Janeiro. Starting with total blood samples, obtained through venopunction, serum was extracted for the plate agglutination technique in order to identify the serum positives for $B$. abortus and for agar gel immunodifusion technique to identify agglutinins for $B$. canis. It was observed that $9,2 \%(n=11)$ of the animals, reacted for $B$. canis but there was no positive reaction for $B$. abortus in any of the tested animals. These results allow us to conclude that it is necessary to promote an awakening of consciousness in Veterinarian Doctors and breeders for the potential risk represented by pet animals non tested for the presence of Brucella and also to point out the urgent need to control that Zoonoses.
\end{abstract}

Keywords: canine brucellosis, Brucella canis, Brucella abortus.

\section{Introdução}

O agente responsável pela brucelose canina, na maior parte dos casos, é a Brucella canis (Larsson e Costa, 1980), mas é fato bastante conhecido que a cadela é receptiva à infecção natural e experimental pelas diversas variedades de Brucella, entre elas a Brucella abortus. A sintomatologia é semelhante e o animal pode albergar essa bactéria nos seus linfonodos por extensos períodos (Brown et al., 1976; Prior, 1976; Bicknell ə Bell, 1979; Poster, 1984; Pidgeon et al., 1987; Forbes, 1990), sendo, portanto, considerada uma doença de caráter sistêmico, contagioso e insidioso (Larsson e Costa, 1980).

Os cães podem adquirir a doença através da penetração dos agentes nas mucosas conjuntival, vaginal e oronasal. A infecção pode ocorrer por acesso dos cães aos microrganismos existentes em aerossóis, alimentos contaminados pelas descargas vaginais de animais infectados, não descartando ainda a contaminação no ato do coito (Currier et al., 1982; Acha e Szyfres, 1986; Germano et al., 1987; Carmichael e Joubert,

\footnotetext{
- Universidade Federal Fluminense - MFL - Rua Professor Hernani de Melo, 101 - Centro - Niterói, RJ, 24.210.130.(moraesia@urbi.com.br)

** Médico-veterinário autônomo

*** Universidade Castelo Branco - Rio de Janeiro, RJ

**** Médicos-veterinários do Centro de Controle de Zoonoses Paulo Dacorso Filho - Rio de Janeiro, RJ
} 
1988; Swango et al., 1992). Menos comumente, a B. canis é transmitida por fômites contaminados, tais como vaginoscópios e seringas contaminadas ou pela inseminação artificial (Germano et al., 1987).

A realização de transfusões sangüíneas com a utilização de animais doadores infectados também constitui uma forma de transmissão da doença, devendo, portanto, ser realizadas a partir de um prévio exame dos animais doadores, constatando a negatividade para a Brucella canis (Peres et al., 1981).

Embora não comprovada experimentalmente, a participação do Rhipicephalus sanguineus na transmissão da brucelose tem sido levantada por alguns pesquisadores (Munford et al., 1975; Godoy et al., 1977; Peres et al., 1981; Germano et al., 1987). Em se tratando de $B$. abortus, normalmente são relatadas as formas de transmissão pela via digestiva através da ingestão de leite, fezes e o consumo de restos de abortamento bovino (Prior, 1976; Bicknell e Bell, 1979; Johnson, 1986; Pidgeon et al., 1987; Scanlan et al., 1989; Allen, 1995), já tendo sido comprovada experimentalmente através de estudos utilizando alimentos contaminados com colônias de Brucella abortus, e confirmando o diagnóstico através de provas sorológicas (Pidgeon et al., 1987; Scanlan et al., 1989).

Embora a maioria dos cães infectados seja assintomática, a literatura demonstra a ocorrência de uma prolongada bacteremia sem febre, ocorrendo normalmente de uma a quatro semanas após a infecção, podendo persistir por seis meses a cinco anos e meio (Acha e Szyfres, 1986; Germano et al., 1987; Carmichael e Joubert, 1987; Nelson e Couto, 1994).

Nas fêmeas pode ocorrer abortamento, sem sinais premonitórios, ao redor do $40^{\circ}$ ou $50^{\circ}$ dia de gestação, seguido de corrimento vaginal esbranquiçado que pode persistir por várias semanas. Também se relata a ocorrência de morte embrionária, reabsorção fetal, falhas na concepção, aumento da mortalidade no período neonatal e anestro (Acha e Szyfres, 1986; Germano et al., 1987; Carmichael e Joubert, 1987; Swango et al., 1992; Nelson e Couto, 1994).

Em machos, o sinal mais comum é a infertilidade, podendo haver orquite, dermatite e úlcera escrotal, prostatite, epididimite, lesões oculares, osteomielites, meningoencefalites, glomerulonefrite e discoespondilite. A dilatação testicular é rara e a atrofia testicular normalmente é unilateral e ocorre em casos crônicos normalmente associados com a esterilidade (Germano et al., 1987; Swango et al., 1992; Nelson e Couto, 1994; Willard et al., 1994; Gomes et al., 1999). Os machos infectados transmitem a enfermidade pelo sêmen e urina, e relata-se que a Brucella canis pode ficar alojada na próstata e epidídimo, sendo eliminada intermitentemente no líquido seminal, mesmo após a bacteremia ter cessado (Carmichael e Joubert, 1988; Kerwin et al., 1992).

A brucelose tem grande importância econômica, especialmente para os criadores, pois a infecção tem uma alta morbidade. Constitui também um problema de saúde pública, já que a população caṇina sem domicílio se infecta e transmite a doença para outros animais e para o próprio homem (Gomes et al., 1999).

Os testes sorológicos são os meios de diagnóstico mais utilizados para detectar a infecção por B. canis e B. abortus (Acha e Szyfres, 1986; Carmichael e Joubert, 1987; Mateu-deAntonio et al., 1993; Nelson e Couto, 1994). E uma vez diagnosticada a doença, deve-se afastar o animal do plantel e começar o tratamento imediatamente (Acha e Szyfres, 1986), através de antibioticoterapia prolongada, como, por exemplo, a Minociclina, ou a associação de Estreptomicina e Tetraciclina por duas a quatros semanas, ou ainda a Quinolona (Fonseca, 1979; Nelson e Couto, 1994). Considerando a localização intracelular do agente etiológico, a eficácia terapêutica normalmente não é total, ou seja, raramente este animal vem a ficar curado, podendo-se, assim, considerar os animais infectados como potencialmente portadores por toda a vida (Acha e Szyfres, 1986; Johnson, 1986; Forbes, 1990; Swango et al., 1992; Allen, 1995).

Recomenda-se testar regularmente todos os animais reprodutores contra Brucella canis, especialmente um mês antes da cobertura. E uma vez infectado, o macho reprodutor não deve retornar ao serviço, mesmo após a terapia com antibióticos (Swango et al., 1992).

Trabalhos conduzidos nos EUA, Japão, México e Peru para investigar a prevalência da Brucella canis na população canina demonstraram que a prevalência variou entre 1 e $28 \%$ (Carmichael, 1966). Já no Brasil, encontram-se relatos de trabalhos conduzidos no Rio de Janeiro e Niterói (Maia et al., 1999), Rio de Janeiro (Vieira et al., 2000), Porto Alegre (Wald e Fernandes, 1977), Belo Horizonte (Godoy et al., 1977), Salvador (Pereira Filho et al., 1978), Campinas (Germano et al., 1987), São Paulo (Cortes et al., 1988), Planalto Catarinense (Schiemper e Vaz, 1990), sendo os resultados bastante variáveis.

\section{Material e métodos}

Foram utilizados 119 cães de ambos os sexos e idades variadas, que deram entrada no atendimento clínico do Centro de Controle de Zoonoses Paulo Dacorso Filho, localizado no bairro de Santa Cruz, na Zona Oeste da Cidade do Rio de Janeiro.

A colheita das amostras de sangue foi realizada com o uso de seringas estéreis descartáveis de $5 \mathrm{~mL}$, a partir de venopunções das veias cefálica ou safena, obtendo-se o volume aproximadamente de $5 \mathrm{~mL}$ de cada animal, sendo todos cadastrados individualmente.

Do sangue, após a retração do coágulo em temperatura ambiente e centrifugação a $3.000 \mathrm{rpm}$ por cinco minutos, foi obtido o soro, que foi transferido para tubos tipo Eppendorf de 2 $\mathrm{mL}$, armazenado e congelado em temperatura de $-18^{\circ} \mathrm{C}$, até o momento da realização das provas sorológicas no CHECKUP Laboratório Clínico Veterinário. ${ }^{1}$ No ato da realização do exame, o processo de descongelamento do soro foi realizado na temperatura ambiente.

Foram utilizados kits para diagnóstico da Brucelose canina produzidos pela TECPAR, ${ }^{2}$ com utilização de antígeno liofilizado constituído de proteínas e lipopolissacarídeos extraídos da Brucella ovis, amostra Reo 198 e soro controle. Foram seguidas as recomendações do protocolo de utilização fornecido pelo fabricante, consistindo de preparo do tampão borato com pH 8,3, ajustado com hidróxido de sódio $0,2 \mathrm{M}$,

\footnotetext{
CHECK-UP Laboratório Clínico Veterinário - Estrada Caetano Monteiro, 818 / 225. Niterói-RJ.

2 TECPAR - Instituto de Tecnologia do Paraná.
} 
salina a $5 \%$ e gel de ágar. Neste experimento, foram utilizadas placas de Petri de $5,5 \mathrm{~cm}$ de diâmetro $\mathrm{com} 0,8 \mathrm{~cm}$ de altura, sobre as quais foram depositados $4,7 \mathrm{~mL}$ de ágar quente, deixando-as esfriar por 15 minutos e levando-as à geladeira por 30 minutos. Foram feitos poços no ágar solidificado com um furador apropriado dispondo de sete pinos perfurantes, sendo um central e seis periféricos, com $3 \mathrm{~mm}$ de diâmetro e $2 \mathrm{~mm}$ de distância entre eles. Em cada poço foi adicionado o volume $20 \mathrm{ml}$ de antígeno na posição central e igual volume de soro-teste e soro-controle intercalados nos poços periféricos. Em seguida, as placas foram acondicionadas em uma câmara úmida e incubadas em temperatura de $25^{\circ} \mathrm{C}$ até que fossem realizadas as leituras com 24,48 e 72 horas. Considerou-se como positivo os casos de ocorrência de uma linha de precipitação nítida entre o antígeno e o soro suspeito.

Já a pesquisa de anticorpos para Brucella abortus foi feita pelo uso da técnica de soroaglutinação rápida em placa nas diluições de 1/25, 1/50 e 1/100, com o antígeno para diagnóstico de brucelose bovina (antígeno de Hudleson) da TECPAR, sendo consideradas negativas as amostras com titulação inferior a $1 / 50$, conforme recomendações do fabricante.

\section{Resultados e discussão}

Nas condições do presente experimento não se observaram soros reagentes à Brucella abortus em nenhum dos 119 animais testados. Entretanto, verificaram-se resultados significativos relativos à soropositividade para a Brucella canis. Estes resultados permitiram constatar que houve uma prevalência de $9,2 \%(n=11)$ de cães reagentes à Brucella canis, conforme pode ser demonstrado no Quadro 1.

Quadro 1 - Positividade e prevalência de B.canis e B.abortus em soro de 119 cães da Zona Oeste da cidade do Rio de Janeiro

\begin{tabular}{|cc|c|c|c|c|c|c|}
\hline \multicolumn{2}{|c|}{ REAČ̃̃ PARA B. abortus } & \multicolumn{3}{c|}{ REAÇÃO PARA B. canis } \\
\hline \multicolumn{2}{|c|}{ POSITIVO } & \multicolumn{2}{|c|}{ NEGATIVO } & \multicolumn{2}{|c|}{ POSITIVO } & \multicolumn{2}{c|}{ NEGATIVO } \\
\hline $\mathrm{n}$ & $\%$ & $\mathrm{~N}$ & $\%$ & $\mathrm{n}$ & $\%$ & $\mathrm{n}$ & $\%$ \\
\hline 0 & 0,0 & 119 & 100,0 & 11 & 9,2 & 108 & 90,8 \\
\hline
\end{tabular}

$\mathrm{n}=$ número

Alguns trabalhos científicos foram conduzidos no Brasil buscando verificar a prevalência da Brucella canis na população canina e os resultados demonstram uma grande variação. Dentre aqueles que encontram uma baixa prevalência, podese citar o que foi desenvolvido no estado de Minas Gerais por Godoy et al. (2000), observando apenas 1,3\% de animais soropositivos, e de Germano et al. (1987) em Campinas, no estado de São Paulo, com 5,4\%. Entretanto, a maior parte dos trabalhos parece sugerir uma prevalência em torno de $10 \%$, como observado por Schiemper e Vaz (1990) no Planalto Catarinense, onde a doença apresentou prevalência na ordem de 9,0\%, por Cortes et al. (1988) na cidade de São Paulo $(7,5 \%)$ ou até mesmo dos trabalhos de Wald e Fernandes (1977) que, analisando cães em Porto Alegre, observaram prevalência de 11,9\%. De forma semelhante, neste estudo foi observada a ocorrência de sororreatividade em $9,2 \%$ dos cães testados. Estes dados estão bastante próximos daqueles apresentados por Vieira et al. (2000) utilizando animais de diversos bairros da cidade do Rio de Janeiro, onde a doença apresentou prevalência na ordem de $9,8 \%$.

Observam-se na literatura alguns valores de prevalência considerados altos, entre eles o relato de Maia et al. (1999) com cães das cidades do Rio de Janeiro e Niterói, onde observaram valor na ordem de $25,7 \%$ e também chama a atenção a citação de ocorrência de cerca de $28 \%$ da população canina em trabalhos conduzidos no México e Peru por Carmichael (1966).

No presente experimento restringiu-se a observar a prevalência da brucelose causada por Brucella canis ou Brucella abortus em bairros da Zona Oeste da cidade do Rio de Janeiro, tendo observado a maior concentração dos casos positivos nos bairros de Santa Cruz e Campo Grande. Mas considerando a localização do Centro de Controle de Zoonoses no bairro de Santa Cruz, e sendo este um órgão público que visa atender a população de baixa renda, acredita-se que a proximidade com o Centro possa ter interferido no resultado.

Em relação à positividade para a pesquisa de Brucella abortus, nenhum dos cães apresentou soropositividade diante do antígeno utilizado. Este fato já havia sido demonstrado por Maia et al. (1999), e pode ser justificado pela falta de contato dos animais analisados com a população bovina, ainda que os bairros analisados disponham de periferia que mantém as características típicas de uma zona rural. Este achado demonstra que não existe reação cruzada entre os antígenos utilizados de Brucella canis e Brucella abortus.

Não foi possível identificar a idade e o sexo de maior predominância entre os animais soropositivos para Brucella canis, pois muitos animais sob estudo foram objetos de doação ou de captura, ou não houve registro de sexo nas fichas individuais fornecidas, dificultando a obtenção desses resultados.

Apesar do número total de animais avaliados não ser muito expressivo para representar a população canina da Zona Oeste da cidade do Rio de Janeiro, o índice de $9,2 \%$ observado pode ser considerado expressivo, pois significa que quase $10 \%$ da população canina que coabita com a humana, serve de reservatório para Brucella canis, expondo ao risco de contaminação não só outros cães, como também os seres humanos com os quais mantêm contato.

\section{Conclusões}

A análise dos resultados permite concluir que é necessário despertar a consciência dos médicos-veterinários e criadores para o risco potencial representado pelos animais de companhia não testados para a presença da Brucella. Além disso, deve-se constituir um alerta para os laboratórios que necessitam adequar-se para o diagnóstico da brucelose com o uso de antígenos específicos, garantindo, desta forma a seleção apropriada de animais doadores de material biológico, especialmente sangue e sêmen, e também das próprias autoridades sanitárias, tendo em vista representar um achado de importância na saúde pública, ressaltando a necessidade premente do controle dessa zoonose. 


\section{Referências}

ACHA, P.N.; SZYFRES, B. Zoonosis y enfermedades transmisibles comunes al hombre y a los animales. Organizacion Panamericana de la Salud, Oficina Sanitaria Panamericana, Oficina Regional de la Organización Mundial de la Salud, 2. ed., Publicação Científica n 503, p.14-36, 1986.

ALLEN, W.E. Fertilidade e obstetrícia no cão. São Paulo: Livraria Varela, 1995. p. 197.

BICKNELL, S.R. e BELL, R.A. Brucella abortus in the bitch: subclinical infection associated with urinary excretion. J. Hyg., v. 82, n. 2, p. 249254, 1979.

BROWN, J.; BLUE, J.L.; WOOLEY, R.E.; DREESEN, D.W. Brucella canis infectivity rates in stray and pet dog populations. Am. J. Public Health, v. 66, n. 9, p. 889-891, 1976.

CARMICHAEL, L.E. Abortion in 200 Beagles. News Report. J. Amer. Vet. Med. Ass, v. 149, p. 1126, 1966.

CARMICHAEL, L.E.; JOUBERT, J.C. A rapid slide agglutination test for the serodiagnosis of Brucella canis infection that employs a variant (M-) organism as antigen. Cornell Vet, v. 77, p. 3-12, 1987.

CARMICHAEL, L.E.; JOUBERT, J.C. Transmission of Brucella canis by contact exposure. Cornell Vet, v. 78, n. 1, p. 63-73, 1988.

CORTES, V.A.; OLIVEIRA, M.C.G.; ITO, F.H.; VASCONCELLOS, S.A. Reações sorológicas para Brucella canis em cães errantes capturados na proximidade dos parques públicos, reservas florestais e em áreas periféricas do município de São Paulo-Brasil. Rev. Fac. Med. Vet. Zootec. Univ. S. Paulo, v. 25, n. 1, p. 101-107, 1988.

CURRIER, R.W.; RAITHEL, W.F.; MARTIN, R.J. Canine brucellosis. J. Am Vet Med. Assoc., v. 180, n. 2, p.132-133, 1982.

FONSECA, A.L. Antibióticos na clínica diária. Rio de Janeiro: Epume, 1979.

FORBES, L.B. Brucella abortus infection in 14 farm dogs. J. Am. Vet. Med. Assoc., v. 196, n. 6, p. 911-6, 1990.

GERMANO, P.M.L.; VASCONCELLOS, S.A.; ISHIZUKA, M.M.; PASSOS, E.C.; ERBOLATO, E.B. Prevalência de infecção por Brucella canis em cães da cidade de Campinas, SP - Brasil. Rev. Fac. Med. Vet. Zoot. Univ. S. Paulo, v. 24, n. 1, p.27-34, 1987.

GODOY, A.M.; PERES, J.N.; BARG, L. Isolamento de Brucella canis em Minas Gerais, Brasil. Arq. Esc. Vet. Univ. Fed. M. Gerais, v. 29, p. 3542, 1977.

GOMES, M.J.P.; DRIEMEIER, D.; SOARES, H.C.; BASTOS, C.D. Brucella canis: isolamento, em um cão com epididimite e orquite. Revista Clínica Veterinária, v.18, p.17-20, 1999.

JOHNSON, C.A. Infertility in the bitch. In: MORROW, D.A. Current Therapy in Theriogenology. Philadelphia: W.B.Saunders Company, p. 466-468, 1986.

KERWIN, S.C.; LEWIS, D.D.; HRIBERNIK, T.N. Diskospondylitis associated with Brucella canis infection in dogs: 14 cases (1980-1991). J.Am Vet Med Assoc., v. 201, n. 8, p. 1253-1257, 1992.
LARSSON, M.H.M.A. e COSTA, E.O. Isolation of Brucella canis. Int. J. Zoon., v. 7, p.125-130, 1980.

MAIA, G.R.; ABBADIA, F.; ROSSI, C.R.S.; VIEIRA, D.K.; MORAES, I.A. Prevalência da brucelose canina nas cidades do Rio de Janeiro e Niterói. Rev. Bras. Reprod. Anim., v. 23, n. 3, p.425-427, 1999.

MATEU-DE-ANTONIO, E.M.; MARTIN, M.; SOLER, M. Use of indirect enzyme linked immunosorbent assay with hot saline solution extracts of a variant (M-) strain of Brucella canis for diagnosis of brucellosis in dogs. Am. J. Vet. Res., v. 54, n. 7, 1993.

MUNFORD, R.; WEAVER, R.E.; PATTON, C.; FEELEY, J.C.; FELDMAN, R.A. Human disease caused by Brucella canis. A clinical and epidemiological study of two cases. J. Amer. Med. Ass., v. 231, p. 1267-1269, 1975.

NELSON, R.W. e COUTO, C.G. Fundamentos de Medicina Interna de Pequenos Animais. Rio de Janeiro: Guanabara Koogan, p. 522-525, 1994.

PEREIRA FILHO, M.; SILVA, J.A.H.; ROCHA, J.V.N. Estudo da incidência da Brucelose canina na zona metropolitana de Salvador. In: CONGRESSOBRASILEIRO DE MEDICINA VETERINÁRIA, 16., 1978, Salvador. Anais..._Salvador, 1978. Resumo.

PERES, J.N.; GODOY, A.M.; BORG,L.; COSTA, J.O. Isolamento de Brucella canis de carrapatos (Rhipicephalus sanguineus). Arq. Esc. Vet. Univ. Fed. Minas Gerais, v. 33, p. 51-55,1981.

PIDGEON, G.L.; SCALANC.C.; MILLER, W.R.; MAYER, T.W. Expenimental infection of dogs with Brucella abortus. Cornell Vet., v. 77, n. 4, p. 339-47, 1987.

POSTER, F.P. Bacteriologia especial:com interesse em saúde animal e saúde pública. Porto Alegre: Sulina, 1984. p. 214-242.

PRIOR, M.G. Isolation of Brucella abortus from two dogs in contact with bovine brucellosis. Can. J. Comp. Med., v. 40, n. 1, p.117-118, 1976.

SCANLAN, C.M.; PIDGEON, G.L.; RICHARDSON, B.E.; BUENING, G.M.; KEMPPAINEN, R.J. Experimental infection of dogs with Brucella abortus. effect of exposure dose on serologic responses and comparison of culture methods. Cornell Vet, v.79, n.1, p.93-107, 1989.

SCHIEMPER, S.R.M.; VAZ, A.K. Inquérito sorológico para brucelose canina por Brucella canis na Região do Planalto Catarinense. Rev. Bras. Med. Vet., v. 12, p. 8-12, 1990.

SWANGO, L.J.; BANKEMPER, K.W.; KONG, L.I. Tratado de Medicina Interna Veterinária. 3. ed. Manole, v. 1, 1992. p.282-283.

VIEIRA, D.K.; MORAES, I.A.; ROSSI, C.R.S.; RAMOS, M.L.M.;BARRETO, L.S. Identificação de cães reagentes à Brucella canis em ambientes rural e urbano no estado do Rio de Janeiro. Rev. Bras. de Ciência Veterinária, v. 7-supl., p. 123, 2000.

WALD, V.B.; FERNANDES, J.C.T. Sorologia da brucelose canina no município de Porto Alegre, RS. Arq. Fac. Vet. Univ. Fed. R.G. do Sul, v. 4-5, p. 92-95, 1977.

WILLARD, M.D.; TEVEDTEN, H.; TURNWALD, G.H. Small animal clinical diagnosis by laboratorial methods. $2^{\text {nd }}$ ed. Saunders Company, 1994. 